\title{
A PEDIGREE OF A FAMILY SHOWING HEREDITARY GLAUCOMA
}

\author{
BY \\ R. R. JAMES \\ LONDON
}

CASES of hereditary glaucoma, though by no means unknown, are yet relatively rare, if we can judge from pedigrees that have been reported; and yet in my opinion the condition is possibly not so uncommon as would appear, and many more pedigrees could probably be constructed by careful inquiry, if we could only find time to go into the family history of each case we see.

The classical example in English ophthalmic literature is that recorded by Lawford in the Roy. Lond. Ophthal. Hosp. Reps., Vol. XVII, p. 57. The latter observer saw several of my cases in consultation and it is largely owing to him that this pedigree has been collected for reproduction here.

(1) A country parson, the eldest child of a family of eight. He died a good many years ago, aged more than 60 years, and so far as is known exhibited no signs or symptoms of glaucoma.

(2) His wife was under the care of Mr. J. Herbert Fisher. She was tirst seen in November, 1912. She had accidentally discovered that the sight of the right eye was defective, and this had been diagnosed by the late Mr. Doyne, in the previous July, as due to glaucoma.

The vision of the affected eye was less than $6 / 60$, the disc was pathologically cupped, and the field of vision was curtailed in an unusual way for glaucoma, the defect being especially in the lower and the temporal side. The most abrupt edge of the cup appeared to be up and in. The tension of the eye was pathologically above the normal; the pupils were equal. Eserine had been used, but did not keep the tension satisfactorily down.

On December 12, 1912, Mr. Fisher trephined the eye. It did not do very well and rather more than a week later the aqueous chamber had not re-formed. Eventually good filtration was obtained, with a shallow chamber and normal tension.

At the end of April, 1914, she had severe pain with vomiting for two days, was the subject of a quiet iritis, and the pupil was blocked. The anterior chamber was absent, and as the eye was of no value visually, painful and likely to give much trouble, it was excised in May, 1914. For the next two years Mr. Fisher was able to keep the left eye under observation, and it retained, with the correction of a small degree of hypermetropia with astigmatism, $6 / 9$ vision. This eye exhibited no signs of glaucoma throughout. The tension kept normal and the field remained good. This lady 
was the eldest child of a family of four, and so far as is known, none of the others showed any symptoms of glaucoma. She died in the summer of 1926 , aged 85 years.

(3) This gentleman was the youngest brother of No. 1 ; both he and his wife (No. 4) had chronic glaucoma, but neither came under my observation, and the fact was supplied to me by one of his nieces, No. 6.

(5) The eldest son is aged more than 60 years. I am informed that he shows no signs of the disease; I have not seen him.

(6) The eldest daughter is a lady, aged 58 years. She had no symptoms of glaucoma, but came to me in September, 1926, with a younger brother, No. 11, to be examined in view of
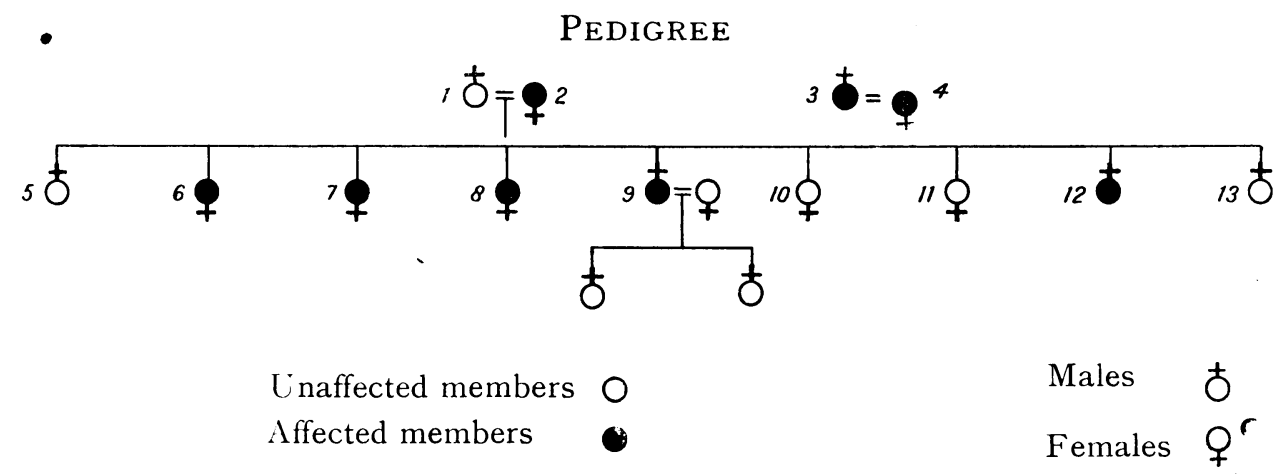

the family history. She was a myope, and had worn glasses for forty years; she had observed no halos. She had the large eyes of a myope, with deep anterior chambers, equal and active pupils, and normal tension in the left eye, while that of the right appeared to the finger to be very slightly above the normal. Her vision was as follows :

Right eye : $-5.5 \mathrm{D}$. sph. $-1.0 \mathrm{D}$. cyl. axis, $50^{\circ}$ in, $=6 / 6$.

Lett eye : $-5.5 \mathrm{D}$. sph. -0.5D. cyl. axis, $50^{\circ}$ in, $=6 / 6$.

With an addition of +2.0D. sph. in each, she read J.1.

The media were clear and the fundus was normal; there was a very small degree of hyperphoria present. The left field and blind spot were normal; the right field showed a defect characteristic of chronic glaucoma, up and in, and slight geneial enlargement of the blind spot. She was ordered to use eserine and reported progress early in October, 1926, when the condition was found unchanged. She had noticed nothing unusual with regard to her vision in the interval. Mr. Lawford saw her, and confirmed the diagnosis, and on December 2 the right eye was trephined with a small basal iridectomy. The only noticeable thing that occurred during the operation was an undue amount 
of oozing of blood while the sclero-cornea was being cut by the trephine. The case did perfectly well.

(7) This lady, the superintendent of a nursing home in London was under the care of Mir. Foster Mioore. Her age was 56 years, and she first had trouble with her eyes in April, 1923, when she complained of seeing a black speck before the left eye. This symptom apparently disappeared, and in May, 1924, she had a recurrence of symptoms, and complained of having had several attacks of defective sight, and she also found that she had otten run into people because she could not see them. Again these symptoms appear to have subsided.

Mr. Foster Moore saw her for the first time on October 27, 1925. Her visual acuity, with correction, was $6 / 6$ in each eye, the tension of each eye was increased, the discs were cupped, and arterial pulsation was present. After consultation with Sir John Parsons, a trephine operation was performed on each eye; the first on November 7, on the left eye, and that on the right, on November 14. When first seen practically the whole of the upper part of the field of the left eye was absent, the defect reaching at one spot almost to the fixation point; the right field showed a defect typical of chronic glaucoma, reaching to within $10^{\circ}$ of the fixation point.

She made an uninterrupted recovery, and when last seen on November 9,1926 , her visual acuity with $+2.0 \mathrm{D}$. sph., was $6 / 6$ in each eye. The visual fields, at this date, showed considerable improvement; in the left eye she had recovered an area of considerable size in the upper temporal field, while in the right eye the defect, though still marked, nowhere came nearer than $20^{\circ}$ to the fixation point.

(8) This lady, a missionary, home from China, aged 54 years, was under the care of Sir John Parsons. There was a six months' history; she had noticed that when reading, the lines above those at which she was actually looking, appeared crooked, and those below also. The vision had become dimmer of late. These symptoms were located in the left eye; she was not conscious of any disability in the right. The eyes externally looked healthy, the pupils were equal and active, the tension in the right eye was normal, while that of the left was very slightly above the normal.

The vision was as follows :

Right eye : $6 / 6,+0.5 \mathrm{D}$. sph. $6 / 5$.

Left eye : $6 / 9$ part, $+1.0 \mathrm{D}$. sph. $6 / 6$.

With +2.0D. sph. added, she read J.1. Each disc was deeply cupped; the left field of vision was contracted almost to the fixation point, the right showed the usual defect in the nasal area. She was admitted to the Royal London Ophthalmic Hospital, and on April 21, 1926, the left eye was trephined, and five days later the same operation was performed upon the right eye. She 
was discharged on June 10, with good central vision, and fields contracted almost to the fixation point in an upper and inner direction. Mr. Foster Moore had an opportunity of examining this case, and found her exceedingly like his own, previously described, only not so far advanced.

(9) This gentleman, aged 53 years, was seen by me on February 12, 1926. He had joined up for war service and had had a remarkably fine war record, having won the D.S.O. When seen he was bordering on a nervous breakdown, due to the illness of his wife. There was a history of very bad vision, without pain, in the left eye of two years duration. His doctor had advised him to see an oculist, but he had omitted to do so, and an optician had informed him that in his opinion the left eye had been defective since birth. Questions after the examination elicited the fact that he had noticed halos since 1918, but as he had had no pain he had paid no attention to them. The right eye had recently showed signs of failure, also painless.

Externally the eyes looked healthy; the right pupil was active and the tension was normal; the left pupil was inactive to light and the tension was slightly raised. His vision was as follows :

Right eye : 6/6 part, not improved with glasses. J.1. with $+1.5 \mathrm{D}$. $\mathrm{sph}$.

Left eye : bare perception of light.

The right disc showed distinct pallor, the vessels tilted towards the nasal side, there was a steep edge to the not very deep cup, upwards. The field showed a typical contraction, reaching to within less than $10^{\circ}$ of the fixation point. The left disc showed a typical glaucoma cup and was very pale; there was arterial pulsation present, and there was a small retinal haemorrhage below the disc. He was ordered to use eserine and reported in a month's time that his sight was not so good. Mr. Lawford saw him in consultation next day, found the tension distinctly raised in the right eye and advised early operation. On March 18 the right eye was trephined with an iridectomy, the coloboma resulting therefrom being nearly complete. The sclerotic was rather vascular. On leaving the nursing home at the end of March the tension was soft and the vision was $6 / 12-0.5 \mathrm{D}$. sph. $=6 / 6$. When last seen on June 11, 1926, everything was satisfactory, the vision with $-0.5 \mathrm{D}$. sph. $6 / 6$, the tension, soft, and the field showed a definite though slight improvement.

(10) This lady, aged 50 years, is a patient of Mr. Wardale of Newcastle-on-Tyne. She complained of no symptoms and consulted Mr. Wardale on account of the family history. She was a simple presbyope and the fields showed no abnormality.

(11) This lady is also under the care of Mr. Wardale. She is aged 48 years. She was seen by him in 1924, when spectacles 
were necessary to enable her to do clerical work with comfort. $\mathrm{Mr}$. Wardale writes to tell me that he saw her twice last year. She complained of occasional halos round a light; these were momentary and if she turned her head away and then looked at the light again, the halo had disappeared. Her central vision was found to be normal and she required a weak spherical glass for reading; the fields were found to be quite normal.

(12) This gentleman, aged 46 years, was under my care. He had been wounded in the left side of the neck during the war, and had a paralysis of the sympathetic nerve on that side. He had had no symptoms and came to be reassured in view of the family history.

Apart from signs due to the sympathetic palsy his eyes showed no abnormality on inspection. His vision was as follows :

Right eye : 6/6 part, +0.25D. sph., +0.25D. cyl. axis, $90^{\circ}, 6 / 5$ part.

Left eye : $6 / 5,+0.25 \mathrm{D}$. sph. $+0.25 \mathrm{D}$. cyl. axis $90^{\circ}, 6 / 5$.

J.1. with +1.0D. sph. The fundus showed no abnormality, physiological cups were noted and the scleral ring appeared to be rather more marked in the right eye than in the left. The left field and blind spot were normal; that of the right showed a very slight defect up and in, reaching, on going over it again more carefully, to within $30^{\circ}$ of the fixation point; it reminded one of the centripetal fan scotoma described by David Priestley smit.: in the Brit. Jl. of Ophthal., Vol IX, p. 233. The blind spot also showed a very slight general increase. He was ordered eserine, and in October he saw Mr. Lawford, who agreed with the diagnosis and advised operation at no very distant date. He came into St. George's Hospital and had a trephine operation performed on October 27. Everything went off satisfactorily, a small basal iridectomy being done. He left hospital after a fortnight and when last seen on December 17 the result was found to be satisfactory. It might be added that when seen on entering the hospital a definite increase in tension in the right eye was observed.

(13) The youngest son, aged 42 years, was under my care. $\mathrm{He}$ was in the Forests Department of the Indian Government and was home on leave. He came to be reassured in view of the family history and was found to be normal. He had had no symptoms and there were no signs of glaucoma, vision being $6 / 5$ in each eye, with full fields and no enlargement of the blind spots.

It should be added that case No. 9 has two sons who are at school. His wife died in the summer of 1926.

In this family we have personal observations on six cases of chronic glaucoma, the eldest and the youngest sons are known to be free from the disease, as also two elder sisters. The 
disease has been of a peculiarly insidious nature and has not, as far as appears, been rapidly progressive in any of the subjects. Cases Nos. 6 and 10 would certainly have been missed by the observer if he had not known the family history, and it might be added that case No. 9, when seen for the first time, entirely omitted to mention the fact that his sister had recently had each eye operated on for glaucoma and that his mother had suffered from the same disease.

I owe a debt of gratitude to Mr. Fisher, Sir John Parsons and Mr. Foster Moore who have collaborated with me in the preparation of this paper and to Mr. Wardale for kindly sending the notes of his cases of which previously I had no knowledge.

\title{
A FAMILY HISTORY OF CHOROIDAL SARCOMA
}

BY

\author{
R. C. Davenport \\ MOORFIELDS RESEARCH SCHOLAR
}

Ar the Annual Meeting of the Ophthalmological Society of the United Kingdom held in 1926 I drew attention to the existence of this family history during the discussion on melanomata. The record is now so striking and so complete that I have thought it worth setting out in full. Two generations have been reported previously in Moorfields' records and more fully by Sir John Parsons in the Trans. Ophthal. Soc. U.K., Vol. XXV, but I am able to add two females of the third generation whose records are at Moorfields.

The first case was treated in 1871 , a woman, aged 38 years, whose left eye was excised for sarcoma. The case is reported by Collins, Lawford, and Marshall in the Roy. Lond. Ophthal. Hosp. Reps., Vol. VII, p. 389 ; Vol. IX, p. 42 ; Vol. XIII, p. 117 (Case 2). She is known to have died seven months after operation from secondary deposits. All this is definite, and there is some less definite evidence showing that her father had an eye removed for some condition, not an injury, and that her twin sister had an eye removed at St. Bartholomew's Hospital, again for something other than injury. Another sister had a tumour removed from the breast at the age of 40 years. I can get no further details of these members of the family. Two daughters of this first case suffered from choroidal sarcoma, the younger having her left eye excised (in 1899) at the age of 19 years, which eye on section contained a typical sarcoma (Collins and Lawford, Roy. Lond. Ophthal. Hosp. Reps., Vol. XIII, p. 117 ; Case 99). Five years later she died from secondary 